\title{
SMALL "PIGTAIL" CATHETER AND FIBRINOLYTIC INSTILLATION FOR MANAGEMENT OF PEDIATRIC PLEURAL EFFUSION
}

\author{
Osama T. Amer; Khaled M. Salah; Mohammed I. Taeema*; Heba G. Enany Emam; Mohammed I. \\ AlAnwar** and Sameh $S$. \\ Pediatrics, Diagnostic Radiology* and Cardiothoracic surgery** Departments, Faculty of Medicine, \\ Zagazig University
}

\section{ABSTRACT}

Background: Pediatric pleural effusion, particularly empyema, is a serious cause of childhood morbidity and prolonged hospitalization. Objective: This study objective was to evaluate the effectiveness of pigtail catheter placement plus alteplase (tPa) instillation intrapleural in treatment of parapneumonic effusion. Methods: A two-arm study was inducted to compare children who treated by pigtail catheter plus intarpleura tissue plasminogen activator (tPa) with children who were treated by thoracostomy tube drainage alone. Also, a cost effectiveness analysis was conducted on the basis of clinical outcomes and cost data available about each treatment strategy group. Result(s): Over the preiod of our study, 46 children were involved in group I with parapneumonic effusion treated by pigtail catheter plus intrapleural TPA and 24 children were involved in group II who were treated by thoracostomy tube drainage alone. The Length Of hospital Stay (LOS) was significantly shorter for $1^{\text {st }}$ treatment strategy (group I) in addition to $0 \%$ failure rate (no surgical intervention needed). Group I strategy of management was the least expensive. Conclusion(s): Pigtail cathter plus intrapleural $\mathrm{tPa}$ is the more effective least expensive treatment strategy in management of children with parapneumonic effusion.

Key Words: pigtail cater, fibirnolytic instillation, pleural effusion

Abbreviations list ;RD, respiratory distress;CTWF, chest tube with fibrinolytic;EP,egyption pound

\section{INTRODUCTION}

A pproximately $40 \%$ of patients who are hospitalized with pneumonia develp parapneumonic effusion, in 5 to $10 \%$ of these patients, the effusion is complicated ${ }^{(\mathbf{1})}$.

Empyema is an important cause of childhood morbidity and long hospitalization and often requires invasive intervention with an increasing worldwide incidence ${ }^{(2)}$.

Empyema is presence of pus in the pleural space and it is calssically divided into thee stages: exudative (simple parapneumonic effusion), fibirnopurulent (complicated parapneumonic effusion) and organized (trapped lung) ${ }^{(3)}$.

Historically, when a patient was diagnosed with complicated parapneumonic effusion, a traditional large bore chest tube was placed resulting in immediate partial pleural fluid evacuation followed by poor drainage on the subsequent $2^{\text {nd }}$ and $3^{\text {rd }}$ post-chest tube days ${ }^{(4)}$.

Consequently, loculated or advanced empyema was diagnosed resulting in surgical debridement techniques such as video-assisted thoracoscopic surgery, minithoracotomy and standard thoracotomy with decortication, resulting in a prolonged hospital stay and morbidity ${ }^{(\mathbf{5})}$.

The use of small multiple bored pigtail cather with intrapleural fibirnolytics has change this manner of practice ${ }^{(6)}$.

Pigtail catheter sonar-guided intrapleural insertion minimizes patient pain, discomfort and limitation of movement as it is smaller and softer than traditional stiff chest tubes. Also, it carries the advantage of being multibored, so, facilitate maximal drainage and shorter length of hospital stay $^{(7)}$

Also, it is recorded that pigtail catter is effective in management of various pleural diseases such as pneumothorax, traumatic, neoplastic, chylothorax effusion, postopreative drainage and lung abscess ${ }^{(8)}$.

Cameron and Davies ${ }^{(9)}$ reported the use of fibrinoytic agents such as streptokinase, urokinsae or alteplase in breaking up loculations for best drainage of complicated parapneumonic effusion.

Cohen et al. ${ }^{(\mathbf{1 0})}$ illustrated the success of medical management of pleural effusion in practice, irrespective of staging on ultrasound scan, promising that closed pleural drainage using small multibored pigtail catter in combination with fibrinolytic instillation and systemic antibiotics, is an effective therapy with a median hospital stay of 5 days and radiological evidence of pleural disease completely resolves within 3 months.

Our objective is to assess the clinical efficacy of treating pediatric pleural effusion by using image-guided pigtail catheter drainage and intrapleural fibrinolytics to conclude the optimal therapeutic options in the context of available outcome measures projecting the most cost effective strategy. 


\section{PATIENTS AND METHODS}

This study was carried out in our Pulmonology Unit, Pediatrics Department, Faculty of Medicine, Zagazig University over a period of 2 years starting from March 2010.

Our study had two groups:

Group I: Prospective arm included 46 patients; $59 \%$ of them were males and the remaining $41 \%$ were girls; their ages ranged from 3 months to 12 yeas. These patients were admitted to our Pulmonology Unit with variable degrees of pleural exudates and managed by the strategy of using sonar-guided pigtail catheter (soft, curled, multihole catheter, small of 8-12 Fr) insertion with fibrinolytic instillation (alteplase, actilyse), 5 points were determined and compared to the retrospective arm group. Furthermore, any adverse events to intrapleural alteplase (Actilys) were recorded.

- Duration of tube drainage.

- Hospital stay length.

- Number of patients needing ICU admission.

- Number of patients who required surgical debridement.

- The overall cost effectiveness of this strategy.

Group II: Retrospective arm included 24 patients; $50 \%$ of them were males and the other $50 \%$ were females. Their ages ranged from 6 months to 9 years. These children were treated by traditional intercostal tube during the two-year period preceding the study. It was reviewed retrospectively to determine the same 5 points.

Pigtail catheter was inserted by "Seldinger technique" by interventional radiologist and sometimes by thoracic surgeon as follows:

- Predrainage checklists: Platelet count and PT, PTT and detection of exact localization of fluid with skin marked " $\mathrm{X}$ " to know optimum site for drain insertion by chest ultrasonography.

- NPO 6 hours before procedure.

- Sedation by IV midazolam at onset of procedure followed by ketamine $(1 \mathrm{mg} / \mathrm{kg})$ with monitoring of $\mathrm{O}_{2}$ saturaiton, RR, HR and blood pressure.

Local anaesthesia at the marked site " $\mathrm{X}$ " is deeply infiltrated in the intercostal space (SC tissue, intercostal muscles, periosteum of the rib and parietal pleura) after raising dermal bleb using $0.25 \%$ bupivacaine $(2 \mathrm{mg} / \mathrm{kg})$.

- Under complete aseptic measures with patient in supine position with the ipsilateral arm raised over the head.

- The needle placed in the mid-axillary line pointing posterior and cephalad.
Neither force nor trocar should ever be

used.

Transitional dilators over wire is used to break up loculation and the tract dilated serially to accept an 8-14 French size pigtail catheter.

Simple X-ray is utilized to document site of chatheter, then it was attached to an underwater seal bottle which must be kept below the level of patients with the tube placed $1-2 \mathrm{~cm}$ under water and when it was available, it was connected to suction device at pressure of $5-10 \mathrm{cmH}_{2} \mathrm{O}$.

Finally, the drain is secured by "purse string" suture or alternatively by special transparent adhesive dressing.

Indications of pigtail catheter placement are:

- Moderate to marked pleural fluid (X-ray).

- Stage II or stage III empyema (sonar).

- Encysted pleural effusion.

Fibrinolytic agent, tissue plasminogen activator and alteplase $0.1 \mathrm{mg} / \mathrm{kg} / 12$ hours) were administrated in the following cases:

1. Chest ultrasound scan revealing "pus, loculations or debris" in stage II or "septations and fibrous tissue peels" in stage III.

2. Persistent radiographic evidence of effusion and suboptimal clinical response (fever and RD) over next 48 hours after catheter placement.

3. If tube drainage is lower than expected.

Expected drainage flow rate:

- Mild pleural fluid: $>50 \leq 100 \mathrm{ml} /$ day.

- Moderate pleural fluid: $>100 \leq 200 \mathrm{ml} /$ day.

Marked pleural fluid: $>200 \mathrm{ml} /$ day.

Statistical analysis:

Data obtained were statistically analyzed using the Statistical Package for Social Sciences (SPSS, Chicago, USA) software version 15.0 for Windows. Results were expressed as mean $\pm \mathrm{SD}$, numbers and percentages. Means were compared using the student's $t$ test while proportions were compared using the chi-square test. A $p$ value of less than 0.05 was considered statistically significant.

\section{RESULTS}

In table (1), There were highly significant differences between the two groups as regard to $1^{\text {st }} 24$ hour improvement and residual radiological findings before discharge and there were no significant differences between the two groups as regard to X-ray opacification.

In table (2), There were high significant differences between the two groups as regard to computed tomography chest requirement. Pigtail group has less chest CT requirement and consequently less hazards of radiation exposure. $100 \%$ of cases in group I complete. Radiological 
resolution occurs after a time period ranging from 2 to 41 days with median of 14-day period. $50 \%$ of group II cases catched complete resolution radiologically after a time period ranging from 1757 days. The other $50 \%$ of group II cases had not reach complete resolution, residual lung collapse and fibrothorax. Furterhmore, they need surgical intervention thereafter.

In table (3), Duration ranged from 2 to 21 days. The maximum duration of pigtail catheter was 18 days. Mean \pm SD was $8 \pm 3.7$ days.
In table (4), Duration ranged from 13 to 43 days. Mean \pm SD was $23.1 \pm 9.2$ days.

In table (5), There were statistically high significant differences between the two groups as regard to outcome measures.

In table (6), There were statistically significant difference between the two groups as regard overall cost.

Table (1): Chest X-ray findings of patients in both studied groups

\begin{tabular}{|c|c|c|c|c|c|c|}
\hline & \multicolumn{2}{|c|}{ Group I } & \multicolumn{2}{|c|}{ Group II } & \multirow{2}{*}{$\mathbf{X}^{2}$} & \multirow[b]{2}{*}{$\mathbf{p}$} \\
\hline & No & $\%$ & No & $\%$ & & \\
\hline \multicolumn{7}{|c|}{ X-ray opacification initially } \\
\hline Encysted & 5 & 10.9 & 0 & 0 & \multirow{4}{*}{2.85} & \multirow{4}{*}{$\begin{array}{l}0.07 \\
\text { (NS) }\end{array}$} \\
\hline Mild & 3 & 6.5 & 0 & 0 & & \\
\hline Moderate & 18 & 39.1 & 9 & 37.5 & & \\
\hline Marked & 20 & 43.5 & 15 & 62.5 & & \\
\hline \multicolumn{7}{|c|}{ Radiologic improvement in $1^{\text {st }} 24$ hours } \\
\hline No & 1 & 2.2 & 0 & 0 & \multirow{4}{*}{17.87} & \multirow{4}{*}{$\begin{array}{c}<0.001 \\
(\mathrm{HS})\end{array}$} \\
\hline Mild & 23 & 50 & 16 & 67 & & \\
\hline Moderate & 1 & 2.2 & 8 & 33 & & \\
\hline Marked & 21 & 45.7 & 0 & 0 & & \\
\hline \multicolumn{7}{|c|}{ Residual radiologic findings before discharge } \\
\hline No & 38 & 82.6 & 8 & 33.3 & \multirow{2}{*}{$X^{2}=17$} & \multirow{2}{*}{$\begin{array}{c}<0.001 \\
(\mathrm{HS})\end{array}$} \\
\hline Yes & 8 & 17.4 & 16 & 66.7 & & \\
\hline
\end{tabular}

Table (2): Ultrasound and computed tomographic data of patients in both studied groups

\begin{tabular}{|c|c|c|c|c|c|c|}
\hline & \multicolumn{2}{|c|}{$\begin{array}{c}\text { Group I } \\
(\text { pigtail + tPa) } \\
(n=46)\end{array}$} & \multicolumn{2}{|c|}{$\begin{array}{c}\text { Group II } \\
\text { (chest tube) } \\
(\mathbf{n}=\mathbf{2 4})\end{array}$} & \multirow[t]{2}{*}{$\mathbf{X}^{2}$} & \multirow[t]{2}{*}{$\mathbf{p}$} \\
\hline & No & $\%$ & No & $\%$ & & \\
\hline \multicolumn{7}{|c|}{ Pleural fluid stage } \\
\hline II & 26 & 56.5 & NR & $\mathrm{NR}$ & & \\
\hline III & 20 & 43.5 & NR & NR & & \\
\hline \multicolumn{7}{|c|}{ CT chest requirement } \\
\hline No & 38 & 82.6 & 8 & 33.3 & \multirow{2}{*}{17} & \multirow{2}{*}{$\begin{array}{c}<0.001 \\
(\mathrm{HS})\end{array}$} \\
\hline Yes & 8 & 17.4 & 16 & 66.7 & & \\
\hline \multicolumn{7}{|c|}{ Complete radiologic resolution (follow up) } \\
\hline -ve & 0 & 0 & 12 & 50 & \multirow{2}{*}{24.35} & \multirow{2}{*}{$\begin{array}{c}<0.0014 \\
(\mathrm{~S})\end{array}$} \\
\hline$+\mathrm{ve}$ & 46 & 100 & 12 & 50 & & \\
\hline
\end{tabular}

NR: Not Reported 
Table (3): Duration of pigtail catheter stay inserted in group I

\begin{tabular}{ccc}
\hline Duration & No & \% \\
\hline$\leq \mathbf{5}$ days & 17 & 37 \\
\hline $\mathbf{6 - 1 0}$ days & 21 & 46 \\
\hline$>$ 10 days & 8 & 17 \\
\hline
\end{tabular}

Table (4): Duration of intercostal chest tube stay in group II

\begin{tabular}{ccc}
\hline Duration & No & \% \\
\hline$<\mathbf{2 0}$ days & 8 & 33 \\
\hline $\mathbf{2 0 - 3 0}$ days & 10 & 42 \\
\hline $\mathbf{3 1 - 4 0}$ days & 4 & 17 \\
\hline $\boldsymbol{> 4 0}$ days & 2 & 8 \\
\hline
\end{tabular}

Table (5): Medical treatment outcome measures of patients in both studied groups

\begin{tabular}{|c|c|c|c|c|}
\hline & $\begin{array}{l}\begin{array}{l}\text { Group I } \\
(\mathrm{n}=46)\end{array} \\
\end{array}$ & $\begin{array}{c}\text { Group II } \\
(\mathbf{n}=\mathbf{2 4})\end{array}$ & $\mathbf{t}$ & $\mathbf{p}$ \\
\hline \multicolumn{5}{|l|}{ Duration of RD (days) } \\
\hline Mean \pm SD & $4.9 \pm 2.2$ & $11.3 \pm 4.1$ & 8.4 & $<0.001$ \\
\hline Range & $2-10$ & $6-19$ & & (HS) \\
\hline \multicolumn{5}{|c|}{ Length Of hospital Stay(LOS) } \\
\hline Mean \pm SD & $16 \pm 4.9$ & $31.7 \pm 12.5$ & 8.7 & \multirow{2}{*}{$\begin{array}{c}<0.001 \\
(\mathrm{HS})\end{array}$} \\
\hline Range & $10-30$ & $17-65$ & & \\
\hline \multicolumn{5}{|c|}{ Failure (surgical intervention) } \\
\hline No & $46(100 \%)$ & $12(50 \%)$ & \multirow{2}{*}{$\begin{array}{c}X^{2}= \\
24.35\end{array}$} & \multirow{2}{*}{$\begin{array}{c}<0.001 \\
(\mathrm{HS})\end{array}$} \\
\hline Yes & $0(0 \%)$ & $12(50 \%)$ & & \\
\hline \multicolumn{5}{|l|}{ ICU requirement } \\
\hline No & $46(100 \%)$ & $17(71 \%)$ & \multirow{2}{*}{21.67} & \multirow{2}{*}{$\begin{array}{c}<0.001 \\
(\mathrm{HS})\end{array}$} \\
\hline Yes & $0(0 \%)$ & $7(29 \%)$ & & \\
\hline Death & No & No & & \\
\hline
\end{tabular}


Table (6): Overall costs and hospital charges by Egyptian pound calculated for patients in both studied groups

\begin{tabular}{|c|c|c|c|c|}
\hline & $\begin{array}{l}\begin{array}{l}\text { Group I } \\
(n=46)\end{array} \\
\end{array}$ & $\begin{array}{c}\begin{array}{c}\text { Group II } \\
(\mathrm{n}=\mathbf{2 4})\end{array} \\
\end{array}$ & $\mathbf{t}$ & $\mathbf{p}$ \\
\hline \multicolumn{5}{|l|}{ Surgical cost } \\
\hline Mean \pm SD & - & $5588 \pm 120.7$ & & \\
\hline Range & - & $5460-5989$ & & \\
\hline \multicolumn{5}{|l|}{ Overall costs } \\
\hline Mean \pm SD & $3022.9 \pm 1244$ & $9116 \pm 1257$ & \multirow{2}{*}{3.27} & \multirow{2}{*}{$\begin{array}{c}0.0016 \\
(\mathrm{~S})\end{array}$} \\
\hline Range & $820-5500$ & $4536-10580$ & & \\
\hline
\end{tabular}

\section{Cost-Effectiveness Scatterplot}

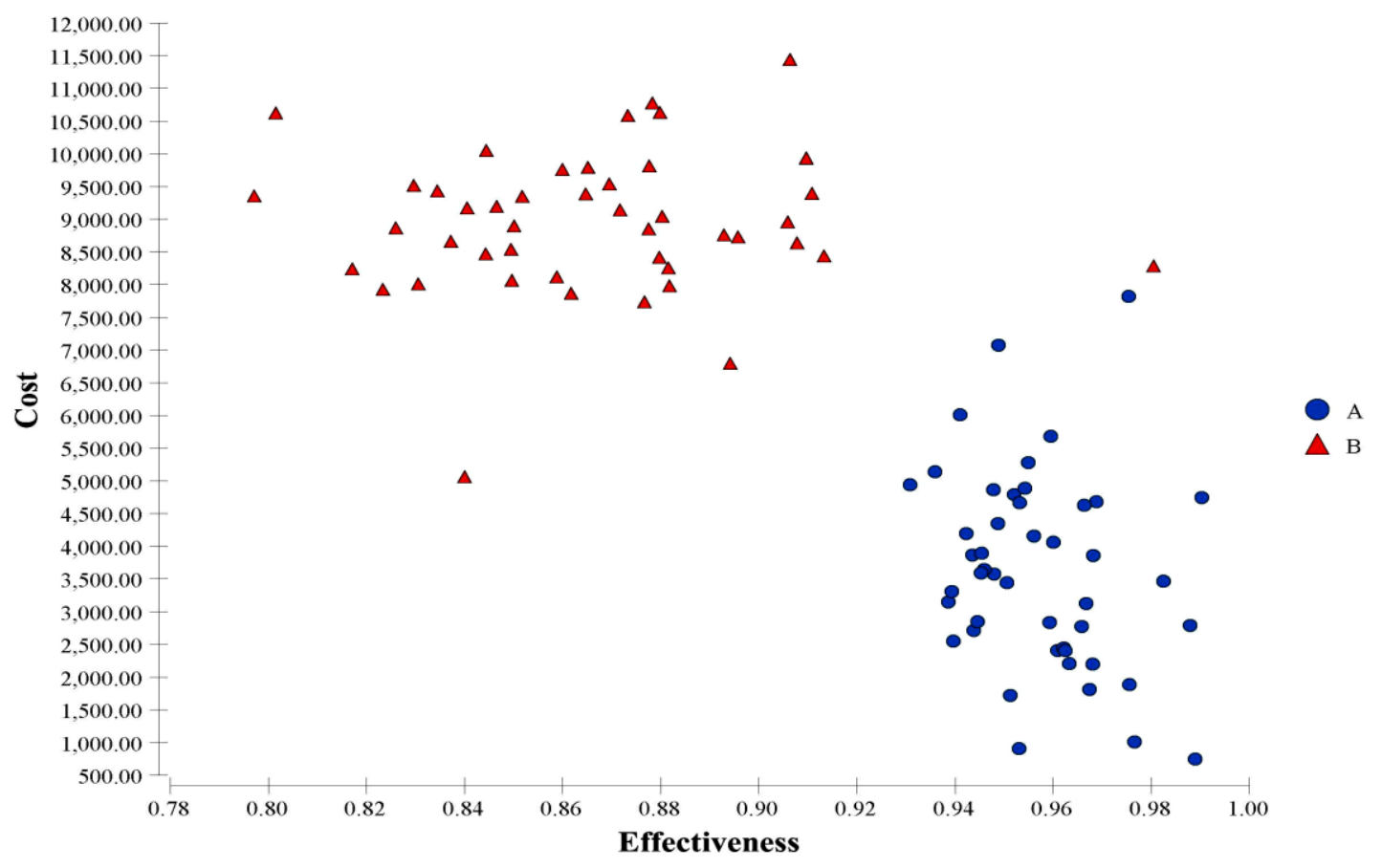

Figure (1): Cost Effectiveness (CE) plot shows a scatter plot for every iteration of strategy A (new alternative) \& B (old standard) reveal that nearly all iterations of strategy A had more effectiveness \& less cost than nearly all iterations of strategy B. 


\section{DISCUSSION}

Throughout the work in our Pulmonology Unit in Zagazig University Hospitals, we face a problem towards pediatric patients treated for pleural effusiosn by intercostal chest tubes. These patients spend long time in hospital with prolonged aggressive courses of antibiotics; many of them fail to achieve complete recovery and frequently need surgical intervention.

We feel sympathy towards our pediatric patients carrying their intercostal tubes for weeks ending with poor clinical outcomes.

By reviewing the literature and hospital protocols concerning this clinical situation, we found that pigtail catheter placement in combination with intrapleural fibrinolytic agent instillation became a standard protocol for management of pediatric empyema in well-known pediatric health centres.

A total of 46 ptaients in group I consisted of $59 \%$ boys and $41 \%$ girls; age range was from 3 months to 12 years and mean age was $3.7 \pm 2.4$ years.

A total of 24 patients in group II consisted of $50 \%$ boys and $50 \%$ girls; age ranged was from 6 months to 9 years and mean age was $2.6 \pm 1.6$ years.

We noticed that the frequent presented age was below the age of 4 in both studied groups. This indicates an increased risk of empyema in children below 4 years old. This may be due to their immature immunity.

Of course, the Egyptian children have an added risk because of lack of pneumococcal and Hib vaccine in the compulsory schedule of immunization.

In our study, X-ray radiographic data showed no significant differences between the two studied groups, it revealed that $39 \%$ of patients have moderate X-ray opacification and $43.5 \%$ of them have marked opacification and $10.9 \%$ were presented with encysted pleural fluids. The radiological improvement in the first 24 hours after pigtail catheter placement and tPA instillation was significantly marked in comparison with the other group (group II).

Group I showed marked improvement in the first 24 hours in $45.7 \%$ of ptaients. However, group II showed moderate improvement in 33\% of patients.

In our study, chest $\mathrm{CT}$ requirement was not routine but was only indicated for selected patients as designed in materials and methods. Patients requiring CT were $8(17.4 \%)$ in group I and 16 patients (66.7\%) in group II which showed a significant difference between the two modalities of treatment. Consequently, the hazard of radiation exposure was less in pigtail plus tPa group (group I).

In a study of 30 children done by Donnelly and Klosterman ${ }^{(11)}$, CT scanning was not helfpul in differentiating empyema from parapneumonic effusion. It has a role in complicated cases only; including initial failure to aspirate pleural fluid, failing medical management, particularly in immunocompromized children, also before surgery to delineate the anatomy and to check for an intrapulmonary abscess.

In this study, $100 \%$ of cases in group I achieved complete radiologic resolution either before discharge or during follow up after a time period ranging from 2 to 41 days with a median of 14-day period. However, only $50 \%$ of patients in group II catched complete radiologic resolution after a time period ranging from 17 to 57 days. The other $50 \%$ of patients in group II had not reach complete resolution, so candidated for surgical intervention.

Our study revealed a highly significnat difference in an important outcome variable which is Length Of hospital Stay (LOS). LOS for group I was $16 \pm 4.9$ days (range, 10-30 days) and $31.7 \pm$ 12.5 days (range, 17-65 days) for group II, showing that pigtail method was effective than conventional chest tube in draining empyema, in combination with alteplase instillation which shortens the length of hospitalization.

Lin et al. ${ }^{(12)}$ recorded also length of hospital stay. For chest tube group, it was $15.5 \pm$ 5.6 days and for pigtail catheter group, it was 17.3 \pm 8.5 days with $p$ value of 0.066 . But, the recorded complications (wound pain, pneumothorax, failure to drain and surgical intervention) were more in chest tube group which made pigtail catheter strategy preferrable.

At toronto, Cohen et al. ${ }^{(10)}$ estimated the cost effectiveness of competing strategies for treatment of pediatric empyema and recorded the LOS as a selected outcome varible; in chest tube group, mean LOS was $22 \pm 7.6$ days and in chest tube with instillation of fibrinolytics, the mean LOS was $6.7 \pm 1.28$. Also, two-way sensitivity analysis of hospital cost per day and length of stay was done, revealing that CTWF is the most cost effective strategy for treatment of pediatric empyema.

In our study, no failure of pigtail drain with fibrinolysis recorded as no surgical intervention needed. However, $50 \%$ of patients (12 cases) in group II (chest tube group) have required surgical intervention (decortication), 7 of them needed ICU care $(29 \%)$. 
Also, Lin et al. ${ }^{(\mathbf{1 2})}$ reported no one in pigtail group requiring surgical interverence (failure rate, $0 \%$ ); howevre, there was one patient in chest tube group needing decortication (failure rate, $5 \%$ ), it was statistically non-significnat because of small sample size.

In our study, the average overall costs were calculated for pigtail catheter with tPA group $(3022.9 \pm 1244 \mathrm{EP})$ ranging from 820 to $5500 \mathrm{EP}$ which was significnatly lower than that calculated for the other study group (chest tube group), mean hospital charges in this group was $9116 \pm 1257 \mathrm{EP}$ (range, 4536-10580 EP).

Sonnappa and Jaffe ${ }^{(13)}$ compared therapeutic management strategies for pediatric empyema and reported mean hospital charges in CTWF group (9127\$) which was significantly lower than that reported for thoracostomy surgically treated group (11.379\$).

Also, in the study done by Gates et al. ${ }^{(14)}$, hospital charges from the non-surgery groups were statistically lower than the surgery groups. Average hospital charges for chest tube with fibrinolytics (CTWF) group was 23473\$, and from chest tube need surgery group was $52474 \$$ depending on hospital resources.

So, we concluded that ultrasonographic guided percutaneous tube drainage with or without fibrinolytics is a safe, effective and less costly alternative to surgery.

Pigtail catheter drainage method appears easier to perform, has few procedures, less traumatic, has less ambulatory limitation, better tolerated by patients than the conventional chest tube thoracostomy due to significant less pain and smaller residual scar, attributed to smaller size and softer texture of pigtail catheters.

\section{CONCLUSION}

- This study provides evidence for the effectiveness of intrapleural tPA in combination with careful sonar-guided pigtail catheter placement in pediatric patients with parapnuemonic pleural effusion.

- Excellent clinical outcomes and complete radiographic resolution of pleural infection in patients who underwent pigtail catheter placement and intrapleural fibrinolytic therapy with no patients requiring surgery.

\section{REFERENCES}

1- Ekingen G, Huvenc BH, Sozubir S, et al. Fibrinolytic treatment of complicated pediatric thoracic empyemas with intrapleural streptokinase. Eur J Cardiothorac Surg 2004; 26: 503-507.
2- Finley C, Clifton J, Fitzgerald JM, et al. Empyema: An increasing concern in Canada. Can Respir 2008; 15: 85-9.

3- Balfour-Lynn IM, Abrahamson E, Cohen G, et al. BTS guidelines for the management of pleural infection in children. Thorax 2005; 60(Suppl.): i1-i21.

4- Peter Feola G, Shaw LCA and Coburn L. Management of complicated parapneumonic effusions in children. Techniques in Vascular and Interventional Radiology 2003; 6(4): 197204.

5- Barnes NP, Hull J and Thomson AH. Medical management of parapneumonic pleural disease. Pdiatric Pulmonology 2005; 39: 127134.

6- Jaffe A and Balfour-Lynn IM. Management of empyema in children. Pdiatr Pulmonol 2005; 40: 148-156.

7- Keeling AN, Leong S, Logan PM, et al. Empyema and effusion: Outcome of imageguided small-bore cater drainage. Cardiovac Intervent Radiol 2008; 21: 135-41.

8- Valusek PA, Tsao K, St. Peter SD, et al. A comparison of chest tubes versus bulb-suction drains in pdiatric thoracic surgery. Journal of Pediatric Surgery 2007; 42: 812-814.

9- Cameron $\mathrm{R}$ and Davies HR. Intra-pleural fibrinolytic therapy versus conservative management in the treatment of adult parapneumonic effusions and empyema. Cochrane Database Syst Rev 2008; 2: CD002312.

10- Cohen E, Weinstein M and Fisman DN. Cost-effectivenes of compteing strategies for the treatment of pediatric empyema. Pediatrics 2008; 21: e1250-e1257.

11- Donnelly LF and Klosterman IA (1997): CT appearance of parapneumonic effusions in children: Findings are not specific for empyema. Am J Roentgenol; 169: 179-82.

12- Lin C, Lin W and Chang J (2011): Comparison of pigtail catheter with chest tube for drainage of parapneumonic effusion in children. Pediatrics and Neonatology; 52: 337 341.

13- Sonnappa S and Jaffe A (2007): Treatment approaches for empyema in children. Paediatric Respiratory Reviews; 8: 164-170.

14- Gates R, Hogan M, Weinstein S, et al. (2004): Drainage, fibrinolytics, or surgery: A comparison of treatment options in pediatric empyema. Journal of Pediatric Surgery; 39(11): 1638-1642. 